\title{
Risk and Opportunity-The Leadership Challenge in a World of Uncertainty-Learnings from Research into the Implementation of the Australian National Disability Insurance Scheme
}

\author{
David Rosenbaum ${ }^{1, *(1)}$ and Elizabeth More ${ }^{2}$ \\ $1 \quad$ King's Own Institute, Sydney 2000, Australia \\ 2 Chief Academic Office, Study Group, Sydney 2010, Australia; EMore@studygroup.com \\ * Correspondence: david@koi.edu.au
}

check for updates

Citation: Rosenbaum, David, and Elizabeth More. 2021. Risk and Opportunity-The Leadership Challenge in a World of

Uncertainty-Learnings from

Research into the Implementation of the Australian National Disability Insurance Scheme. Journal of Risk and Financial Management 14: 383.

https://doi.org/10.3390/jrfm14080383

Academic Editor: Gregory W. Brown

Received: 28 July 2021

Accepted: 16 August 2021

Published: 17 August 2021

Publisher's Note: MDPI stays neutral with regard to jurisdictional claims in published maps and institutional affiliations.

Copyright: (c) 2021 by the authors. Licensee MDPI, Basel, Switzerland. This article is an open access article distributed under the terms and conditions of the Creative Commons Attribution (CC BY) license (https:// creativecommons.org/licenses/by/ $4.0 /)$.

\begin{abstract}
This paper considers the risks and opportunities inherent in a major national change process through a descriptive approach to the implementation challenges for Australian non-profit disability service providers as they grapple with the implementation of the transformational National Disability Insurance Scheme (NDIS). It highlights the leadership challenges associated with the newly developed NDIS Implementation Framework and, in doing so, recognises the risk and opportunity issues contained with that implementation process. The research used grounded theory coupled with framework analysis in a qualitative study that, in part, sought to identify leadership characteristics deemed necessary to minimize risks, capitalize on opportunities, and support positive change outcomes leading to successful NDIS implementations amongst several participating organisations, each with differing demographics and at different stages in the implementation process. The findings, which have been grouped into phases, suggest a range of leadership attributes at key phases of the NDIS implementation that are necessary to minimise implementation risks and maximise opportunities associated with the NDIS. These phases have been identified as: (i) An input phase where the emphasis must be on internal change preparedness and external environmental impacts and drivers; (ii) A process phase where the emphasis is on direct implementation issues; and (iii) An outcomes phase where active consideration needs to be on organisational mission sustainability, as well as the risk and opportunity challenge. The study is crucial in revealing leadership challenges and lessons for large scale change and risk management in the non-profit sector, within and beyond the specific case of Australia's NDIS implementation, useful for both scholars and practitioners.
\end{abstract}

Keywords: change management; non-profits; grounded theory; framework analysis; risk; transformational leadership; servant leadership

\section{Introduction}

Australian non-profit organisations have often contextualised risk from a conservative perspective and, in doing so, have rarely considered the risk/opportunity dichotomy. Informative texts on risk in this sector have tended to focus on its management, but not generally on the context of the other side of the coin, this being opportunities (Herman et al. 2004). This stems from historic funding models that have affected many in this sector, where heavy reliance on government grants and philanthropic donations have largely been the mainstay of their operations (Baulderstone and Earles 2009). Even the language of non-profit funding has previously played a limited role in their overall activities (Foster et al. 2009).

The introduction of the NDIS pointed to the development of a new approach to market mechanisms, with a focus given to 'market expansion', where a pronouncement regarding a "Market Enablement Framework" (NDIS 2018) for service providers was to become the 
direction for future service provision. This Framework was described as the "NDIS Market Approach: Statement of Opportunity and Intent" and focused on such issues as 'Building consumer and community capacity'; 'changing market settings'; and 'commissioning a service' (NDIS 2018). Wording and emphasis in this document presupposed a necessary new direction in the future of non-profit service providers needing to focus on sustainability and expansion of service delivery. Underpinning this, assumed within the document's messaging was the importance of considering new opportunities, but concomitantly, a need to consider risk in a different light to the former approach of funding the disability sector.

The NDIS represents generational change in the manner in which disability support services are designed, delivered, and funded, where a supply driven process is moving towards a demand-driven process. This has wide-ranging implications for the sector, both from the perspective of service providers as well as service users. This is regarded as a generational shift given that the existing system, being pre-NDIS, has been in operation for many decades.

The implications of these changes are many and include the following:

- the manner in which non-profit service providers structure their businesses, both organisationally as well as financially, as they face the real risk and ongoing dilemma of financial sustainability in the context of government imposed financial caps on service delivery pricing;

- the manner in which they approach the market from a competitive perspective, having never dealt with the levels of competition now being faced as a result of the private for-profit sector being invited into a competitive service delivery role;

- the lack of certainty regarding future funding of the NDIS. As recently as July 2021, the NDIS shows a 33\% cost blowout, year-on-year, representing AUD 6.6 billion (Australian Financial Review 2021). This places disability service providers in the unenviable position of having to potentially face a new reality, namely reduction in allowable pricing caps on a wide range of service delivery options. Socially, this places service users at risk of not having their allowable 'funding packages' accepted in full, but also places service providers at risk of spending substantial resources in developing services in response to client needs yet having these services either underfunded by the NDIS, or, in the worst case, having funding being withdrawn altogether.

This research considers the challenges associated with the changes resulting from the NDIS from the perspective of the non-profit service provider, a large and specific segment of the overall market. In doing so, it seeks to identify the leadership challenges involved in dealing with both the risks and the opportunities that the NDIS presents to this sub-sector-the non-profit disability services sector.

Accordingly, the key research question is: what is the nature of leadership necessary for non-profit disability service providers to achieve success in fully implementing the NDIS? A subsidiary question deals with a related issue, regarding: how should these organisations respond to the sustainability issues that they now face about the operations of the NDIS?

\section{Literature Review}

The relevance of current leadership theory to the broader non-profit sector has developed from the narrow trait and behaviour focus on leadership, through concern for situational context and contingency approaches, to acknowledging the leader/follower relationship approach, a servant leader approach, and the transformational versus transactional leadership and collaborative styles, with more recent concerns about emotional intelligence and authentic leadership. These have been developed primarily on for-profit organisations in the leadership theory domain (Osula and Ng 2014). Additionally, leadership in the for-profit sector has traditionally been the basis for understanding leadership in the non-profit sector (Levesque 2020).

Therefore, how relevant is traditional leadership theory for the non-profit sector in the context of the NDIS rollout? Additionally, given the environmental turbulence 
emanating from the introduction of the NDIS with its consequences of a competitive funding regime, challenges to staff morale and to upholding organizational mission, what types of leadership are crucial in the sector to minimise risk of failure and enhance success? What new skills and leadership styles are necessary in NDIS implementation in a change management context and process requiring innovation and transformation for many nonprofit organisations?

As far back as a decade ago there have been calls to extend strategic leadership research beyond the for-profit sector into the non-profit sector, alongside wide-ranging debates about whether traditional strategic leadership theory is indeed applicable to non-profit organisations (Cheverton 2007; Shakely 2004; Inglis 2004). In this regard, linkages between transformational leadership and non-profit organization mission and objectives have been identified in the prevailing literature (Seyhan 2014).

Examples have appeared of the contribution of strategic leadership to organizational performance around the areas of learning and change capacities, organizational context and innovation, managerial wisdom, and the mission trajectory of an organization (Phipps and Burbach 2010). Finding both similarities and differences between the two sectors in using such theory, they suggested that a multilevel research approach be adopted, grounded in terms of effective non-profit strategic leaders who: increase the organization's learning capacity; increase the organization's capacity for change; improve organizational performance through the exercise of managerial wisdom; understand the effect organizational context has on their behaviours; contribute to improved organizational innovation; and contribute to 'mission trajectory'.

Others have argued that organizational context impacts the leadership process (Rowold et al. 2014) and, consequently, there are indeed differences in non-profit strategic leadership (Thach and Thompson 2007). Certainly, the notion of leadership as critical to the non-profit sector has been raised, with some exploring the notion that servant leadership is particularly relevant to non-profit organisations. Whilst our research has confirmed this view, recent research has challenged this, claiming that servant leadership may constrain rather than empower followers, and impact levels of organizational commitment (Palumbo 2016). This was not borne out by our research reported in this paper. Support for non-profit transformational leadership, however, remains strong in recent research work, including ours, especially in comparison with transactional leadership (Aboramadan and Kundi 2020).

Other research has investigated the positive aspects for business outcomes of transformational leadership as they relate to both for-profit and the non-profit sector, hypothesizing that any significant differences occur as leaders focus on unique problems and opportunities affecting leadership styles (Freeborough and Patterson 2016). This has also supported the importance of transformational leadership in the non-profit sector but led to a call for much more research for a truer picture of whether for-profit leadership theory is relevant to the non-profit sector.

Notwithstanding the emphasis in research on transformational leadership in nonprofit research, especially in change situations, some (Rowold et al. 2014; Seyhan 2014) have found that it is important to explore leadership constructs using multiple leadership theories rather than from a single theory perspective, demonstrating that the effectiveness of various leadership constructs do differ between the two sectors.

This is not surprising given the real differences we have discovered in our research. Areas of difference can include: focus on mission rather than profits; a focus on social problems; organizational objectives; legal and regulatory frameworks; volunteers; demographic differences (gender or age); philanthropy; a wide range of stakeholders (including more government ones); more financial constraints; governing boards; diverse functions; remuneration; diverse funding sources, including reliance on funding by external, often government bodies; tasks; requirements; fewer hierarchical structures; values orientation; collaborative approach; different performance expectations; a different mix of clients and services; greater technology challenges; competition with the private sector; increased com- 
petition for talent; and growing demands for accountability from both clients and funders. Moreover, there is increased focus on the importance of performance metrics in the human service sector, especially given the delays experienced between design, implementation and performance outcomes (Osula and $\mathrm{Ng}$ 2014).

Finally, more recently, the multidirectional management (Levesque 2020) required in non-profits is very different to for-profit leaders, with CEOs managing up to boards, managing down to staff and clients, and out to stakeholders, including government agencies, donors, community, and with other non-profits collaboratively, often in advocacy roles. Pertinent to the research reported herein is Levesque's (2020) suggestion that leaders in the disability service sector must develop more creative and innovative programs to respond to client needs. This level of creativity must result from refocusing the capabilities within these organisations to compete effectively in a more open marketplace, enabling non-profit service providers the ability to effectively position themselves in a competitive environment. This places transformational leadership at the centre of these organisational leadership requirements, whilst also allowing for the relevance of servant leadership as an effective approach within non-profit sector organisations.

Certainly, in the types of change management required for successful implementation of the NDIS, transformational and servant leadership approaches tend to prevail in our research, with a democratic, not autocratic, style, rather than the more incremental transactional approach. Transformation leadership can have a positive effect on staff and organizational performance, on job satisfaction, and a greater capacity for adaptability and resilience in the face of change challenges and risks. This is characterized by emotional intelligence, a focus on both individual and organizational needs and objectives, and inspires through a macro vision grounded in the organisation's altruistic social goals and value system (do Adro and Leitão 2020). The positive dimensions of servant leadership in change processes are also supported by the recent literature (Roberts 2020).

Dealing with the NDIS implementation has and will continue to challenge a range of non-profit service providers as the marketplace shifts from a supply driven system to a demand driven one. This transition moves service provision away from the priorities of service providers, who traditionally have received government funding based on the volume and type of services provided to people with a disability. Under the new NDIS model, service users are now able to apply the proceeds of pre-determined funding packages, through the NDIS, to effectively source the services they require to fulfil their lifegoals, meaning that their demand for services will now drive the market in disability services. Furthering the risks for non-profit service providers in this shifting market, is the fact that NDIS is also registering for-profit service providers, meaning that competition in this new marketplace is now multi-directional, that is, between non-profit service providers, but also between non-profit and for-profit organisations.

The challenges are, therefore, many, and highlight the risks, as well as the opportunities in such a new marketplace. Issues of business development processes needed in a competitive marketplace are clear. Additionally, a move from the pre-NDIS block funding to a post-NDIS unit funding means that the financial management skills of many of these smaller non-profit service providers may be challenged. Finally, sourcing and retaining skilled staff in such a competitive and expanding market could risk organisational sustainability moving forward (Andrews 2018, 2019).

\section{Methodology}

The aims of this research are to assess the way non-profit disability service organisations implemented the NDIS and, in doing so, evaluating the leadership implications from an industry-wide understanding of the risk and opportunity trade-offs that service providers need to consider. These trade-offs are very much embodied within the sustainability issues that would be relevant when considering the future of these organisations in a changing environment. Given such a focus, a qualitative analysis methodology was identified as the appropriate method for pursuing this aim. To achieve this aim, the researchers 
deployed the two compatible approaches of Grounded Theory and Framework Analysis (Rosenbaum and More 2021).

In terms of Grounded Theory, the ingredients of symbolic interactionism have underpinned its development, focussed on understanding and interpreting patterns of human behaviour (Chenitz and Swanson 1986). It is these patterns which are being studied and provide the foundations for the inductive approach to the development of theory. The coding process involved in this method enables the researcher to develop the analysis of the interview data to the point of naturally identifying the linkages between raw data and core variables, deemed necessary to this theory development (Boychuk Duchscher and Morgan 2004).

The analysis of interview data followed a defined structural process for grounded theory application that was developed by the authors in earlier grounded theory research (Rosenbaum et al. 2016). That process involved several procedural elements that, when combined, identified a grounded theory of change management in the non-profit hospital sector derived from a single case study application. These included the following:

- Coding interview transcripts (using Nvivo software);

- $\quad$ Linkage Review Memos that were developed on an iterative basis in parallel with a detailed Research Log;

- $\quad$ Node Interrelationship Mapping at two distinct iterative levels;

- Node Groupings at lower levels and iteratively developed in conjunction with Higher Level Nodes that involved detailed descriptive characteristics.

Given the wide-ranging applications and interpretations of grounded theory as a widely used method in qualitative research, recognition of the ongoing development and adaptation that each application makes to original theory has been an accepted approach in the prevailing literature (Morse et al. 2009). This is further reinforced by the general recognition of adapting methodology to individual research settings (Denzin and Lincoln 1994).

In terms of Framework Analysis, the application of analysing interview transcripts to undertake thematic analysis across many individual cases and in the context of retaining the contextual connections at the interviewee level (Gale et al. 2013), further strengthens the overall qualitative framework within which we, as qualitative researchers, can develop inductive theory. One of the distinctive features of Framework Analysis is the creation of thematic matrices and locating interviewees within it (Kiernan and Hill 2018). This enables linkages to be identified between themes and participants.

Framework Analysis in this research was applied to the development of the grounded theory, which informed the development of the NDISIF ("National Disability Insurance Scheme Implementation Framework") (Rosenbaum and More 2021). Through an iterative process, a thematic framework was developed, following the structured analysis of all interview data as identified earlier. Flowing from the thematic framework, which identified nineteen high level themes, ten unique theory elements were finalised. These were then structured to identify the completed NDISIF, which became the model that, based on the prevailing analysis of all interviews and the 600+ pages of interview transcripts, informed how success in implementing the NDIS could be achieved by non-profit disability service providers.

Interviews were conducted in seven non-profit organisations across Australia. These organisations were of varying sizes, ranging from turnover of less than AUD 500K through to turnover of greater than AUD 50M. In total, 46 interviews were conducted with staff from across these organisations, from frontline service delivery staff through to board members. The focus of these interviews was aimed at understanding the personal perceptions and feelings of the employees, how these were dealt with by the organisation, and how these impacted on the processes and outcomes of the NDIS implementation processes, feeding into a better view of the risks and opportunities with which each organisation dealt.

These interviews, some of which were undertaken face-to-face, whilst others were undertaken via teleconference links, were all audio recorded as a basis for developing detailed transcripts. They were approached on a semi-structured and open-ended basis 
so as to ensure maximum engagement with the interview participants. Additionally, this approach provided the basis for thick rich descriptions of the interviews to support theory development (Birks and Mills 2011).

The semi-structured open-ended interview questions appear in Appendix A to this paper.

\section{Findings}

These findings have been identified in the context of the phases of NDIS implementation and beyond, and reflect on the leadership challenges faced by those involved in planning and implementing planned organisational change. An overview of the NDIS Implementation Framework appears in Figure 1.

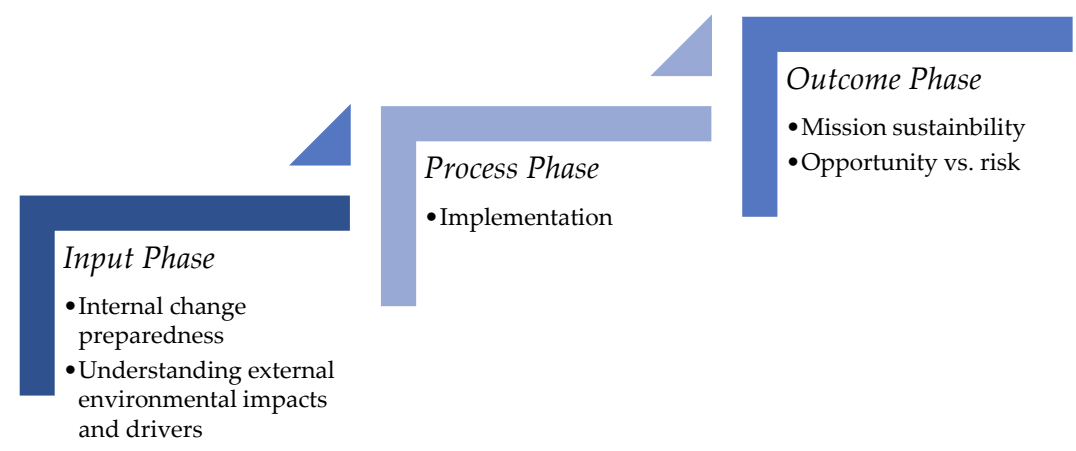

Figure 1. NDIS Implementation Framework—The High-Level Context.

\subsection{First Phase-Change Readiness}

- Cultural change

Our research reinforces the role that organisational alignment plays in fostering cultural change. Such alignment between organisational culture and individual values underpins change outcomes during and after the change process. Such alignment takes into consideration the varying sub-cultures that exist within the organisation. This ensures that, whilst a predominant culture is identified and developed, everyone within the organisation is aligned and that sub-cultures, whilst they may exist and be representative of the varying service offerings across departments, do not conflict with the predominant culture. Ideally, if managed well, they can reflect a rich internal organisational diversity that encourages change and the take up of opportunities, rather than stifling them.

- $\quad$ Sector specific change management

Whilst organisational change management has been analysed and researched across the commercial sector over many years, our research suggests that a sector specific approach to the management of such change, within the context of its risk appetite, may yield better outcomes and potentially improve success rates. This highlights the necessity for considering change management from a non-profit specific perspective, rather than merely adapting commercially based approaches. Accordingly, it is suggested that the development of an approach to change should be one that focuses on a range of non-profit specific considerations rather than accepting a generic change management approach that may ignore the importance of linking sector attributes to change methodologies.

- Organisational foundations

Our research further suggests that several necessary organisational components must be evident for change to be effective. These include organisational structures that enable and support change; Human Resource functions that are activated throughout the change process, including, pre-, during, and post-change, as well as addressing head-office syndrome for those organisations that have multiple sites. For many of the organisations involved, risk of failure arose from structural and process inflexibility, limiting the many opportunities the NDIS offered for sustainability and growth. 


\subsection{Second Phase-Implementation}

- $\quad$ Service utility

Our research has also identified the need for NFP disability service providers to better, and more clearly, define the appropriateness of the services they provide to key stakeholders in a competitive environment characterised by client demand rather than service availability. This follows directly from the funding structures as represented in both the client packages as well as the approved pricing contained within the pricing schedules of the NDIS which effectively limit the amounts that providers can charge for the entire range of their services.

\section{- Communication}

The nature and style of the language of change has also been identified in our research as an important element to successful change outcomes. This includes the way internal communication is undertaken, through to the way language of change is embraced by change recipients. A further element with regards communication, correlated to some extent with organisational structure as discussed earlier, is the extent to which a diversity is both allowed and encouraged, as evidenced through the application of bottom-up as well as top-down communication, making this an iterative process, distinct to a mono-directional and instructive approach.

- Externality

Our research suggests that, given the heavy dependency by service providers on the activities of the Agency (NDIA), as well as on the communications to and from the Agency, a proactive approach to Provider/Agency engagement is necessary for effective change at the provider level. Our research indicated that the effective use of external sector networks was a vital component and supported participating organisations in achieving their strategic objectives.

\section{- Financial}

Recognition of unique aspects of financial management in non-profit organisations has been of some consideration in existing research (Chabotar 1989; Lancksweerdt et al. 2021; Searing 2018). Our research suggests that the renewed focus on effective financial management at a unit-cost level of service provision is vital during NDIS implementation and, if ignored, may adversely affect future sustainability, thereby threatening the viability of these non-profit disability service providers. NDIS Implementation processes must ensure the adequacy of their financial management resources to cope with these new demands, including the need for enhancing financial literacy through training and, in many cases, developing a financial mindset for those who have not previously had to consider in their roles the financial implications of the services they offer.

Failure to consider these crucial aspects appropriately was a risk to implementation success.

\subsection{Third Phase-Organisational Sustainability}

\section{- Mission maintenance}

As these non-profit service providers are heavily mission-driven, maintaining an adequate focus on this mission during the organisational change was found to be an important element to successful change, especially considering the challenges of aligning the mission values of their staff with the now commercial priorities which the sector has been forced to embrace. Diminishing the mission focus considering the need for a more commercial focus was a key risk during implementation. When mission and commerciality were well balanced, growth opportunities arose and could be taken.

\section{- Opportunity and Risk}

Our research suggests that non-profit service providers can best achieve desired organisational change with regards the NDIS implementations if they are able to manage the shift from a typical non-profit conservative risk profile to a more expansive risk profile. 
This can be achieved through a shift away from a view of the NDIS posing a range of risks to the organisation, and towards understanding the wide-ranging opportunities that may be available through a process of visioning the unknowns in a new marketplace environment and responding to these.

The above research findings are contextualised in a leadership response, where the challenge is clearly focused on leadership in a world of uncertainty for non-profit disability service providers implementing the NDIS. In this context, transformational leadership becomes a central focus of leaders in this sector, whilst elements of servant leadership also provide a range of characteristics that our research has shown to be critical in ensuring the transition is successful, especially given the mission-centric challenges that abound. Accordingly, servant leadership has been identified as an appropriate underlying approach to leadership in this sector, where a clear operational clarification of its precise characteristics is necessary. In this regard, we have reinforced the notions of empowerment, humility, authenticity, interpersonal acceptance, direction, and stewardship as the fundamental elements (Van Dierendonck 2011).

\section{Discussion}

\subsection{Change Process}

Our research suggests that, in the context of the non-profit sector, a balance needs to be maintained between strict procedural and more flexible approaches to the management of organisational change. In this regard, leadership, as well as the cultural characteristics discussed below, provide support for the effectiveness of such change practices, whilst adaptability remains a fundamental element. To support such an approach, guidance which highlights a fully adaptable approach to organisational change, can focus on the variability of the planning phase, the execution phase, as well as the end phase of organisational change. This was supported by a number of interviewees as evidenced in the following sample quotes:

"So, I think one thing we really want to build ... is purpose ... the tactical changes ... what are the social impact goals that we want to align ourselves to, to give people a little more purpose ... " [when responding to questions of what drives the changes in your organisation]; and

" ... what's really difficult is because it's such a casualised workforce so it's not the same ... " and "... but everybody needs to be treated fairly, equally and supported well in the role that they do". [when responding to questions regarding unique characteristics within the organisation when designing change]; and

“. .. just to get through the day with the clients' support ... As for the NDIS and the policies and procedures that go with it, it was a nightmare, to be quite honest, and it's taken me until now to unravel everything ... " [when discussing the external pressures that impact change in this specific sector]

The current research further supports earlier research which has identified important elements of Lewin's change model as relevant to the current research outcomes (Lewin 1946). This is despite his model being erroneously described as a linear three-step model when, in fact, it contains substantial additional elements that more accurately should be identified as an iterative model, especially when we consider the additional elements of action research, group dynamics and force field analysis, as depicted in Figure 2. 


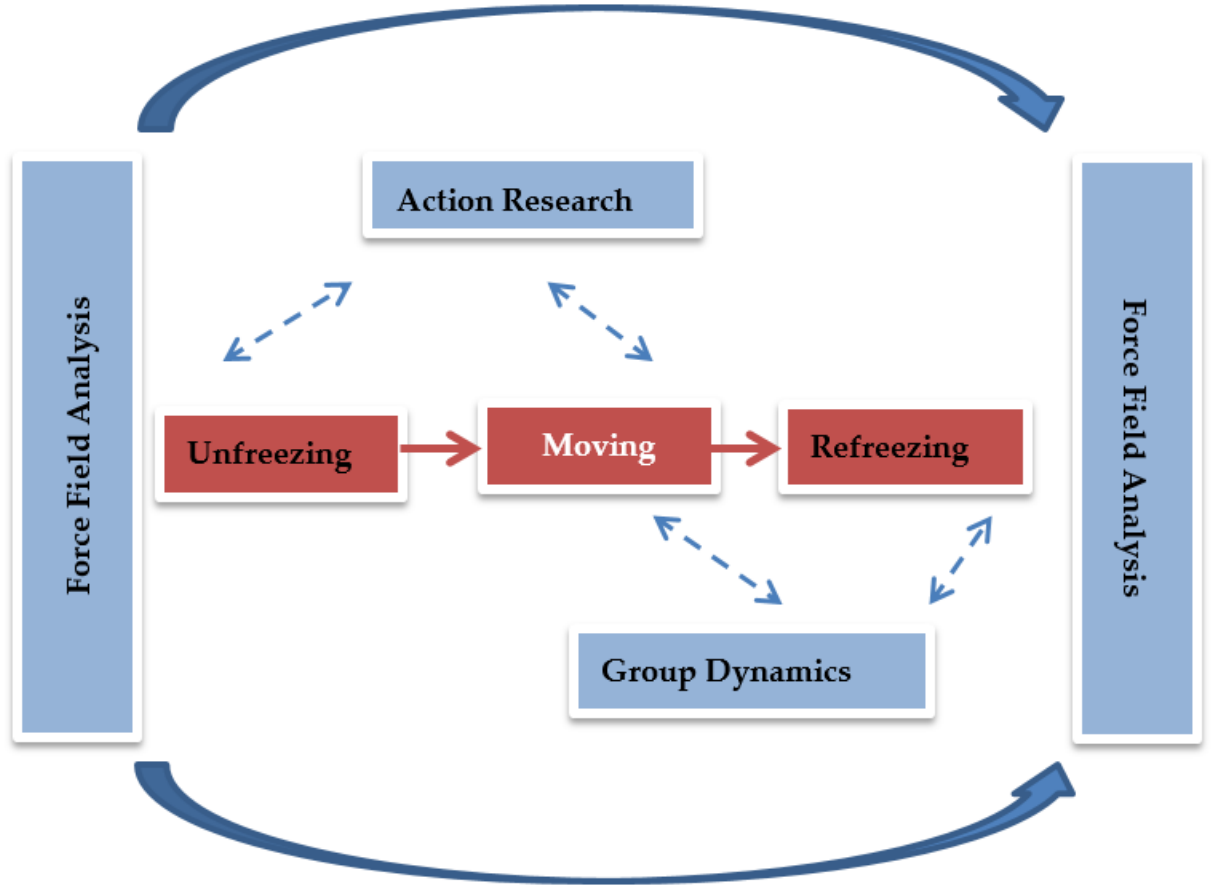

Figure 2. A more accurate view of Lewin's change model. Reproduced from Rosenbaum et al. (2018).

Lewin's approach, when applied to the implementation of the NDIS, underpins a wide range of organisation-specific actions and informs the phases identified earlier. At the Inputs Phase, it enables leadership to consider issues of visioning; change resistance; technical preparedness; and training that that addresses skills gaps, as well as emotional response strategies necessary to support staff through the transitioning processes. Recognising the importance of this Inputs Phase is evidenced by a number of quotes from interviewees including the following:

“They call it burnout, and I think a lot of it is because you're working, I wouldn't say long hours or anything like that. It's just that it's working with disability people is not easy, unless you've had education, and I think that's the main thing that needs to be done". [when commenting on how staff respond to different client situations and the impact this has]; and

"I'm sure that people who have an expertise and a passion around being person centred and individualised funding packages would probably leave the organisation, but we have a CEO who's really quite focused and conscious on staff wellbeing and she would manage that very closely". [when responding to the impact that leadership style has on staff dealing with their emotions]; and

“We don't have any good reporting systems. So, I think from a change point of view, some of that stuff could have been done a lot better and earlier". [when discussing a range of preparedness challenges]

At the Process Phase, change leadership enables these elements in the inputs phase to be consolidated and applied as the process of implementation takes hold. This enables training to be further developed and focused on specific needs, some of which may become more apparent during this process phase; staff support programs being implemented and further refined based on need and on consultation with all staff and refining internal communication structure and messaging. The relevance of the Process Phase is evidenced by a number of quotes from interviewees including the following:

"I think sometimes we do feel like we're the last to know about things, which you know, might have an impact on our clients or-and what we need to do for them, so it can be a bit frustrating at times". [commenting on their organisa- 
tion's historic approach to communication which was addressed during the live implementation]; and

"I was really shocked, for such a caring industry, how they treated its people. Because I came from a commercial [organization] which you think, you know, is very opposite. I just felt people were very unvalued that worked within the organisation. In just over a year, this changed very much. Very much for the better, in my view. A lot more engagement and a lot... In just over a year, huge changes". [explaining the manner in which the organisation was responsive to its shortcomings during the implementation]; and

" ... the organisation really went above and beyond to support me, I think, in particular, with any area that I was making mistakes with. It was, I think, being patient". [explaining the manner in which support was provided during the implementation of new systems and processes associated with the NDIS rollout]

At the Outcome Phase, change leadership provides the opportunity to consolidate the previous phases in support of the sustainability of the organisation, and doing so from the perspective of maintaining the pre-implementation mission. This enables the pre-existing values of the organisation to continue in line with the many expectations of its staff, as well as its clients. As confidence in the change grows internally, staff develop affinity with the new systems and processes and feel a sense of optimism about the future. Force Field Analysis supports this entire change process (Baulcomb 2003) whilst consolidating strategic opportunities and evaluating ongoing risks. Reflective processes in an ongoing change management environment (Mcardle and Reason 2008) support leadership flexibility across a wide spectrum of organisational initiatives, as systems and processes are bedded down, usually with ongoing refinements in a continual cycle of improvement. Finally, Group Dynamics enable key positioning to take place throughout the organisation to support both the change process and the consolidation aspect of the change (Lucas and Kline 2008). This is in keeping with the detailed approaches to Lewinian change. The Outcome Phase was supported by a number of quotes from interviewees including the following:

"I guess a recognition that it was difficult and challenging and we were asking staff to do things in a different way. Staff have come into this field of work with one set of values and beliefs, and we have asked them to turn that on its head and start thinking of the business head and looking at money and commodifying an hour of service" [identifying the conflict that became apparent during the transition that needed to be dealt with in order for the implementation of the NDIS to move forward]; and

"My reflection on all of this is that as someone now, I would go into a change like that and not think it was all on me". [a CEO of one organisation responding to how formal and informal reflection impacted on their own development through this process]; and

"Well, look, I think that the key challenge, because I do believe that now we have the processes in place and I think that we have the right staff and I think that we are so- - there is less things that we don't know, so we know, but I think that the biggest challenge is, you know, how to sustain, how to be sustainable". [identifying the key issue of organisational sustainability in the context of the current business model]; and

"I think there needs to be a little bit more risk taking, sort of informed risk taking. I would see that as really important ... like being able to sort of try and take the policy and create your practice and your future, I think there needs to be a little bit more of that". [responding to the future challenges in the context of prevailing cultural issues] 


\subsection{Non-Profit Culture}

As far back as 2000, the prevailing literature of the time (Weisbrod 2000) argued the evidence for a growing commercialization of non-profit organisations, despite the seeming paradox of linking commercialism with the non-profit sector, often regarded as representing different cultures. This was subsequently confirmed by other researchers in this field (Child 2010). Yet, others wrote of the blurring of boundaries between business, government, and non-profit sectors (Bromley and Meyer 2017). More recently, the tension between commercial and social missions in non-profits and social enterprises became apparent, emphasizing the strain between being mission driven to achieve social goods and profit making, throwing up issues of integrity for many in such organizations (Powell and Bromley 2020; Golensky and Hager 2020). This has been previously conceptualized as the mission-integrity problem (Bielefeld 2013) or mission-market tension (Laidler-Kylander and Stenzel 2013) for organisations seeking to balance social and commercial objectives. This is a major risk aspect of NDIS implementation, as mentioned above. Yet, pressure remains on non-profit organisations to manage their operations differently in order to address this changing landscape, grounded in shifting the focus from a purely mission and values driven framework, and thereby representing a change to existing organisational culture (Osula and $\mathrm{Ng}$ 2014). Such values then determine culture, and culture determines the approach to change management, with cultural competence required at all levels for successful change. The issue of values congruence is central, a risk without its achievement and an opportunity for competitive success if achieved.

In our research, we too found people struggling with a changing mindset, being the need to balance their organisation's commitment to social purpose and mission with a turn to more rationalization and the market, necessitated by government funding changes to the sector with the introduction of the NDIS - a tension between heart and head in the need to be more accountable and sustainable (Anheier and Toepler 2020). It was also clear that our organisations had to go beyond purely financial and organizational sustainability, to consider personal sustainability at the service delivery end of the spectrum. In some cases, staff were able to absorb mental and process paradigm changes, though it was unclear that full acceptance was reached during the period of our study, thus leaving us to ponder if and when full acceptance might actually be embedded. For others, there was a concern about whether or not the organisations were, from a values perspective, effectively 'selling themselves out' in order to survive the new legislative and administrative demands. It was not clear if the challenge of retaining strategic mission commitment, alongside commercial viability, and its impact on culture might become easier over time, and if this shift from mission-based non-profit to a more commercial framework had been appropriately handled originally and, thereafter, accepted at a deep or superficial level. As one senior staff member stated:

"I guess a recognition ... that it was difficult and challenging and we were asking staff to do things in a different way. Staff came into ... this field of work with one set of values and beliefs and we have asked them to turn that on its head and start thinking of the business head and looking at money and commodifying an hour of service ... and so that has been a big change for people, and whilst I think intellectually my team understand that, I think emotionally they find it very difficult" [explaining mindset and cultural shifts during the change process]

The externally imposed changes by government also did not include support for actual service provision but, rather, expected this to be supplied by service providers, necessitating a change in the psyche of service delivery. Sometimes there was the challenge of over servicing, and the failure to understand that now service was actually costed and had to be reported, underlying the financial risks to NDIS organisations. This change of staff responsibilities towards increased paperwork was regarded as challenging service delivery objectives in relation to mission and redefining what service delivery now encompassed. This was often true in our study, especially with professionals such as psychologists and social workers. Furthermore, needing to become more commercially 
adept and focused made further demands on often highly risk averse cultures in terms of needing to incorporate a business and marketing orientation, increased understanding of costs, use of social media, and a view of effectively 'selling' welfare products-changes which some found uncomfortable. Staff also had to grapple with the change in the concept of advocacy-from doing so broadly in the sector to now advocating for clients' packages to ensure they receive the services they need.

The most successful of our research organisations understood the impact of the NDIS external changes required their culture to be flexible, adaptable, and innovative (do Adro and Leitão 2020; Seyhan 2014). We observed key cultural characteristics to be regarded as being supportive, inclusive, empowering, and accountable. This was also seen in another recent Australian study of the NDIS focused on social innovation (Taylor et al. 2020) that found the most productive cultures for social innovation involving innovative service design were characterized by openness, inclusiveness, receptivity to new ideas, reflexivity, and tolerance of dissenting views. Their research revealed, as did ours, the importance of the social justice objectives of non-profit organisations guiding innovations, and a focus on opportunities, especially in enhancing client services, instead of risks, greater than the mere challenge of implementing the NDIS system.

Our research also raised the issue of whether culture supported the NDIS change or to what extent the NIDS implementation itself was a catalyst driving culture change. Certainly, and surprising to us, the research also revealed that, rather than the changes impacting mostly on frontline service delivery staff, often the most affected were staff in backroom operations, especially those involved with finance and technology. Additionally, again surprisingly, the role of HR staff in many of our sites was not as central as one would have imagined, an issue directly affecting and affected by change leadership styles.

Another aspect of the cultural changes associated with the implementation of the NDIS, as indicated earlier, is the new focus on financial management throughout the organsiations. This has resulted in leadership maintaining a very close eye on the cost of program development, as well as the cost of service delivery. Given the manner in which the NDIS pricing schedule is structured and the pricing limits being placed on service delivery, this focus starts at the unit costing level. In this way, the skills associated with management accounting now become a much needed skill within these non-profit service delivery organisations.

Shifting mindsets in an environment where financial management becomes a vital cog in the implementation of a major social and economic policy has challenged many in this sector, as evidenced by a range of comments from interviewees, including:

"I had to liaise a lot with finance, and dude, everyone was a number. Everyone was just a number with an amount next to it. Like, but each one of those people on that Excel sheet, had a story, had a family, had a relationship, had a tragedy in there. [when describing the necessary changes in the approach to their clients as a result of the financial constraints imposed by the NDIS], and

"People do understand that we have no choice but comply to the rule, but, as I mentioned before, we finance, administration, CEO-delivers some of the bad news". [when identifying the impact of restrictions resulting from financial imperitives associated with service delivery

\subsection{Emotional Support}

As has been recently suggested: "Every job has an emotion culture ... As recognition and appreciation grows for the emotive component of work, greater awareness of the emotive burdens of a job contribute to a fuller understanding of what is required to fulfill responsibilities" (Guy 2021, p. 391). Therefore, the issue of emotional support for employees during the major transformation change wrought by the NDIS implementation is an important concern for leadership throughout the organisations involved. Such support relates to a variety of factors such as physical resources, processes, structure, 
human resource practices, perceptions of trust, and how psychological safety can be ensured and enhanced.

There is also the need to take note of perceived fairness in how such support by leaders and managers is provided across the organisation, including in different groups that might be central or at the periphery of the institution, resulting in a healthy emotional climate during the change processes involved (Lee 2021). The best of the organisations in the study started well before the NDIS pilots, optimistic about the opportunities possible, and dealing with change, uncertainty and stress, which alleviated much of the risks and problems later on. For others, there was "a high burnout rate", high staff turnover, and the struggle to find and retain talent continues in the sector as an ongoing risk in successful NDIS implementation.

The need for emotional support was evident across all the organisations involved in the study, especially in the early days of implementation, as the following interviewee quotes illustrate: "NDIS is stretching us in new ways we never imagined ... many organisations have people seriously distressed"; and "Hanging in there by the skin of our teeth ... Baptism of fire"; and "Staff still struggling with changing mindsets"; as well as "Office based team burnt out by the process-driven by client management system and complexity of the NDIS and staffing issues"; and "Took a long time to get people through change fatigue relating to changing to a business model"; and further "Stress from casualization of the workforce-low morale regarding time sheets-we have to account for every minute" and "Culture change-hands now in more pies ... had to learn a lot and get onto a different level of reporting back ... leading into the corporate world with a business hat".

There was also another challenge, as exemplified in the following interviewee comments: "Clients are in control but many are aggressive", and, as one staff member suggested, "the CEO has a strong focus on clients and families and did not see the impact on staff until later on".

The role of Human Resources was also limited across many organisations, affecting emotional support, as the following quote implies: "Support from HR—sits out of their capacity to effect change".

A range of useful ways of providing emotional support have been identified (Guy 2021), from regular staff meetings through to introducing wide-ranging approaches that encourage self-awareness and self-regulation aimed at improving employee resilience in dealing with emotionally draining and challenging work. This is supported by building trust through information sharing and transparency, adequate communication, and strong leadership at all levels (Kähkönen 2020). Most of these were tools used by our sample organisations to some effect, as indicated by one leader: "Managers held discussions and let their frustrations out among themselves", and "A culture of consultation. Information sharing all the way down". One also pointed out the organisation had a "Coping culture rather than formal support".

Additional approaches were widely canvassed and these included leader/manager forums; quarterly newsletters; regular CEO updates; one-on-one supervisor meetings on a regular basis, fortnightly team meetings; improved induction processes; increased information days for staff and clients; involvement of CEO and senior teams in NDIS meetings where problem sharing lead to solution development; increased visibility of the CEO; improved access to Employee Assistance Programs, as well as increased use of social media. Unsurprisingly, there were critiques such as: "We need to share information in a smarter way", and "Too many emails and cascade structure doesn't work ... don't rely on emails for communication".

\subsection{Skills Development}

Leaders and managers need to be competent in managing change and further enhancing organisational change capability, especially for those in the non-profit sector where NDIS changes can threaten sustainability, plus the stability of mission, values, norms, and beliefs as mentioned earlier. One recent study found that middle manager capabilities 
positively influenced an organisation's capacity for change and, indeed, organisational performance (Sukoco et al. 2021). Moreover, recent research in the non-profit sector established a link between the effective management of organizational change and leader interaction skills in order to meet stakeholder demands (Addai-Duah 2020).

Alongside change management competency is developing innovative capabilities and competence (Lei et al. 2021) in an increasingly dynamic non-profit sector, key to effectively managing the change brought by the NDIS. Moreover, positive linkages between change management factors and innovative behaviour within the context of organizational innovation (Sung and Kim 2021) are influenced by communication and participation during change.

Transformational leadership is central in stimulating an organisation's change competency and its culture of organizational innovation. In order to develop both, leaders and managers need to enhance training and retraining throughout the institution, mindful of differences in employee roles and positions, their experience, and diverse levels of education and training (Ha and Le 2021). As one of our CEO interviewees put it succinctly: "Manage the present while creating the future".

In the research, much change was needed, but four key areas required special attention:

- Developing a commercial mindset whilst maintaining a client care focus;

- Acquiring financial acumen;

- $\quad$ Learning computer/IT skills (including using mobile devices);

- Learning new systems and processes.

Training had not been financially supported by the NDIA, and many organisations did not have adequate resources for training. Therefore, networks were crucial for many organisations for keeping up to date with new programs, activities, and training opportunities. One small organisation organised training for learning change processes-not just talk, but how to do the change, be change, and make it appear, and including facilitated training days for the board across governance matters. Another, larger, successful non-profit service provider focused a lot on training: "Content Management System training for mental health, first aid and suicide training to all in the team, case worker refresh training; and public speaking". In an organisation struggling with the challenge of technology: "Staff were supported by challenges from the new data base leading to stress, alleviated by new data entry training for staff".

Other approaches identified by interviewees included:

- $\quad$ online e-learning attached to induction;

- $\quad$ design of internal courses as well as access to external courses;

- $\quad$ individual support for completion of Certificate 3 programs;

- individual professional development;

- $\quad$ front line supervisor training;

- customer service training;

- $\quad$ specific innovation meetings;

- wellness days;

- finance training; as well as

- $\quad$ training for accreditation purposes.

Throughout the changes, senior leadership support was crucial, as one interviewee stressed: "The CEO comes into all the support worker training", and another that "All internal training with the organisation is going above and beyond to support".

The most demanding changes related to: "Needing more innovative thinking-need to be more commercially minded". This went beyond simple training and development to culture change over time, led by the CEO and senior leadership teams. One approach was using: " . . the Language of change - trying to be a change agent ... moving from managers to leaders in the new world". More pragmatically, some of the sites had hired commercially experienced staff to develop a more commercially oriented culture, whilst also keeping to the fundamental vision and mission of the organisation. Sometimes 
this caused resentment, but as one employee said: "Our CEO brought in commercially experienced people adding value to the organization". Here, opportunity was sensibly balanced with risk. Some critiques included: "Leadership development needs to be more formalized and amplified"; and "Lack of leadership but no leadership training"; "Lot of training but often not targeted", and "The issue of attracting and retaining a quality workforce".

\section{Limitations}

Whilst this study has been able to research across a diversity of organisations implementing the NDIS, there are limitations created in such breadth to compare the leadership styles of similar organisations, especially across size, location, and resources. Moreover, it would be important now to explore how the sector's leaders have dealt with NDIS under the COVID-19 pandemic conditions which occurred after our research had concluded. A key test in the future is that with the escalating costs of the NDIS scheme, the issue of resource acquisition and management in a competitive environment will prove an even more severe test of leadership than previously, for all in the non-profit disability sector and the NDIS scheme.

\section{Conclusions}

The sustainability and success of non-profit organisations is fundamentally predictable whether or not they have effective leadership (Norris-Tirrell et al. 2018). Additionally, while this is also true to some extent in the for-profit sector, it is the crucial scaffolding in the non-profit sector. This becomes even more of an issue when we consider the focus of such social change initiatives as the NDIS which will have a profound impact on the manner in which people with disabilities are able to secure their place in a society that both values them and is prepared to minimise discrimination against them. This can only be recognised and achieved through a process of enabling their access to wide-ranging services that others within society take for granted. A key implication of our study is that this has never been truer than in the adoption and implementation of Australia's NDIS. Those organisations which have benefitted most from the scheme have had leaders willing to move beyond the sector's traditional conservative leadership style to a transformative one that raised risk appetites and grasped opportunities for the betterment of organisations and clients. This also means that there is an increased need for this sector to be able to attract, reward, train, and retain leaders for ongoing sustainability, growth, prosperity, and the many challenges facing them into the future. The war for talent continues at all levels.

More specifically, the winners increased their organisation's change management and learning capacity; improved performance of individuals and the institution through diverse training and development opportunities for leaders and managers throughout the organisation; encouraged innovation, especially in structural, technological, and process reform; maintained the mission at the heart of the organisation whilst embracing a requisite commercial orientation that demanded financial acumen; adopted appropriate communication at all levels; and all this within the context of maintaining a healthy organisational culture that interacted well with its portfolio of stakeholders, including the important external government and regulatory bodies. The most successful organisations, who benefitted the greatest from the NDIS scheme, also had leaders who had developed excellent relationships with their boards.

Indeed, the best of our organisations revealed how they had dealt effectively with what one recent study of strategic leadership in the non-profit sector (Reed 2021, p. i) found were the key characteristics differentiating such leadership from the for-profit sector:

" ... the mission/margin tension of multiple bottom lines; the diffused, influencebased power structure needed to respond to multiple stakeholders; the critical nature of the nonprofit leader/board relationship; the importance of strategic communication skills to build understanding and maintain mission alignment; and the need to go beyond metrics to individual stories to convey mission impact". 
Our research has evaluated the role that leadership has played in the implementation of the Australian National Disability Insurance Scheme for non-profit service providers. It has identified the uncertain nature of the external environment that has challenged the existing supply driven approach to one that reflects the demands of service users. In doing so, it has developed its findings in the context of the risks and opportunities that such service providers must evaluate if they are to survive in this new economic and service delivery structure. Leadership, when seen through this risk and opportunity prism, must be able to adapt to such changing landscapes.

Author Contributions: Both authors contributed to all sections of the paper. Both authors have read and agreed to the published version of the manuscript.

Funding: This research was in part funded by three industry partners from within the Australian non-profit sector including Koorana Child and Family Services Inc. (Sydney, Australia); Junction Works Ltd. (Melbourne, Australia), and Wayside Chapel (Sydney, Australia).

Data Availability Statement: Data comprises interview transcripts which resulted from recorded interviews. The transcripts are held on file by the researchers whilst the interview recordings were destroyed once the transcripts were completed for each interview.

Conflicts of Interest: The authors declare no conflict of interest.

\section{Appendix A. Semi Structured Open-Ended Interview Questions}

\section{Appendix A.1. Questions Related to How Change Was Managed}

1. How would you describe the internal communication processes that were undertaken before and during the changes, on an interpersonal, group and organisation-wide basis?

2. How would you describe the broader stakeholder communications that were undertaken at various points in the change process, from the perspective of clients, families and supporters, NDIA and any others?

3. As a staff member what do you believe were your personal support requirements that were necessary to help you through the change processes that were undertaken?

4. Thinking of your support requirements, how did the organisation respond to these from the perspective of co-workers, supervisors and the broader organisation?

5. Overall, how would you describe the change processes within the organisation

6. What forms of communication media were most commonly used?

\section{Appendix A.2. Questions Related to Leadership Attributes and Characteristics}

1. Thinking of the leaders in your organisation, from team leaders through to the CEO and the Board, how would you describe the role that these various leaders played during the change processes?

2. What leadership characteristics or behaviours do you believe supported the change processes?

3. What leadership characteristics or behaviours do you believe may have hindered or negatively impacted the change processes?

4. When thinking of different leaders across the organisation, what personal attributes or characteristics do you believe impacted the change processes and outcomes?

\section{Appendix A.3. Questions Related to Organisational Culture}

1. How would you describe the culture of this organisation?

2. Are there clear subcultures across the organisation and do they support or detract from the main organisational culture?

3. Can you describe any cultural shifts that you have noticed during the change processes within the organisation?

4. What specific cultural attributes of the organisation have impacted, positively or negatively, on the organisational changes that were deemed necessary to implement the NDIS? 
5. How do you relate to the market-based cultural requirements that underpin the NDIS?

6. What role do you believe the board played during the change processes?

\section{References}

Aboramadan, Mohammed, and Yasir Monsoor Kundi. 2020. Does Transformational Leadership Better Predict Work-Related Outcomes Than Transactional Leadership in the NPO Context? Evidence from Italy. VOLUNTAS: International Journal of Voluntary and Nonprofit Organizations 31: 1254-67. [CrossRef]

Addai-Duah, Charity. 2020. Nonprofit Church Leaders' Perceptions and Lived Experiences Involving Innovation Competency and Change Management: A Phenomenological Study. Columbia: Walden University.

Andrews, Kevin. 2018. Market Readiness for Provision of Services under the NDIS. Canberra: Joint Staning Committee on the NDIS.

Andrews, Kevin. 2019. NDIS Planning Interim Report. Canberra: Joint Standing Committee on the NDIS.

Anheier, Helmut, and Stefan Toepler. 2020. The Routledge Companion to Nonprofit Management. London: Routledge.

Australian Financial Review. 2021. August 9. Available online: https://www.afr.com/policy/health-and-education/ndis-not-doingthe-job-20210808-p58gua (accessed on 9 August 2021).

Baulcomb, Jean Sandra. 2003. Management of change through force field analysis. Journal of Nursing Management 11: 275-80. [CrossRef]

Baulderstone, Joe, and Wendy Earles. 2009. Changing Relationships: How government funding models impact relationships between organisations. Third Sector Review 15: 17-36.

Bielefeld, Wolfgang. 2013. The role of accountability in fostering nonprofit integrity. In Integrity in Organizations. Berlin: Springer, pp. 174-91.

Birks, Melanie, and Jane Mills. 2011. Grounded Theory - A Practical Guide, 1st ed. London: Sage Publications Ltd.

Boychuk Duchscher, Judy, and Debra Morgan. 2004. Grounded theory: Reflections on the emergence vs. forcing debate. Journal of Advanced Nursing 48: 605-12. [CrossRef] [PubMed]

Bromley, Patricia, and John Meyer. 2017. "They are all organizations": The cultural roots of blurring between the nonprofit, business, and government sectors. Administration \& Society 49: 939-66.

Chabotar, Kent. 1989. Financial ratio analysis comes to nonprofits. The Journal of Higher Education 60: 188-208. [CrossRef]

Chenitz, Carol, and Janice Swanson. 1986. From Practice to Grounded Theory: Qualitative Research in Nursing. Boston: Addison Wesley Publishing Company.

Cheverton, Jeff. 2007. Holding our own: Value and performance in nonprofit organisations. Australian Journal of Social Issues 42: 427-36. [CrossRef]

Child, Curtis. 2010. Whither the turn? The ambiguous nature of nonprofits' commercial revenue. Social Forces 89: 145-61. [CrossRef]

Denzin, Norman, and Yvonna Lincoln. 1994. Handbook of Qualitative Research. London: Sage Publications, Inc.

do Adro, Fransisco, and Joao Leitão. 2020. Leadership and organizational innovation in the third sector: A systematic literature review. International Journal of Innovation Studies 4: 51-67. [CrossRef]

Foster, William, Peter Kim, and Barbara Christiansen. 2009. Ten nonprofit funding models. Stanford Social Innovation Review 7: 32-39.

Freeborough, Robert, and Kathleen Patterson. 2016. Exploring the effect of transformational leadership on nonprofit leader engagement. Servant Leadership: Theory E Practice 2: 4.

Gale, Nicola, Gemma Heath, Elaine Cameron, Sabina Rashid, and Sabi Redwood. 2013. Using the framework method for the analysis of qualitative data in multi-disciplinary health research. Journal of Medical Research 13: 117. [CrossRef] [PubMed]

Golensky, Martha, and Mark Hager. 2020. Strategic Leadership and Management in Nonprofit Organizations: Theory and Practice. Oxford: Oxford University Press.

Guy, Mary. 2021. Harnessing Human Capital for Peak Performance. In The Public Productivity \& Performance Handbook. Edited by Marc Holzer and Andrew Ballard. London: Taylor \& Francis.

Ha, Tung, and Phong Le. 2021. What Are the Sources of Organizational Change Capability? The Role of Transformational Leadership and Organizational Justice. International Journal of Business Administration 12: 2. [CrossRef]

Herman, Melanie L., George L. Head, Peggy M. Jackson, and Toni E. Fogarty. 2004. Managing Risk in Nonprofit Organizations: A Comprehensive Guide. Hoboken: John Wiley \& Sons.

Inglis, Loretta. 2004. Alternatives To The "Heroic" Leader: An Investigation of Distributed Leadership in Nonprofit Organisations. Available online: https://bridges.monash.edu/articles/journal_contribution/Alternatives_To_The_Heroic_Leader_An_ Investigation_Of_Distributed_Leadership_In_Nonprofit_Organisations/5091499 (accessed on 9 August 2021).

Kähkönen, Tiina. 2020. Employee trust repair after organizational change. Journal of Organizational Change Management 33: $1143-61$. [CrossRef]

Kiernan, Matthew, and Mick Hill. 2018. Framework analysis: A whole paradigm approach. Qualitative Research Journal 18: $248-61$. [CrossRef]

Laidler-Kylander, Nathalie, and Julia Stenzel. 2013. The Brand IDEA: Managing Nonprofit Brands with Integrity, Democracy, and Affinity. Hoboken: John Wiley \& Sons.

Lancksweerdt, Lode, Tom Van Caneghem, and Anne-Mie Reheul. 2021. Accruals Management to Avoid The Current Ratio Falling Below One: An Empirical Analysis Among Nonprofits. Nonprofit and Voluntary Sector Quarterly 50: 578-97. [CrossRef] 
Lee, Helena. 2021. Changes in workplace practices during the COVID-19 pandemic: The roles of emotion, psychological safety and organisation support. Journal of Organizational Effectiveness: People and Performance 8: 92-128.

Lei, Hui, Linnan Gui, and Phong Le. 2021. Linking transformational leadership and frugal innovation: The mediating role of tacit and explicit knowledge sharing. Journal of Knowledge Management 25: 1832-52. [CrossRef]

Levesque, Mario. 2020. Leadership as interpreneurship: A disability nonprofit Atlantic Canadian profile. Politics and Governance 8: 182-92. [CrossRef]

Lewin, Kurt. 1946. Action Research and Minority Problems. Journal of Social Sciences 2: 23-46. [CrossRef]

Lucas, Colleen, and Theresa Kline. 2008. Understanding the influence of organizational culture and group dynamics on organizational change and learning. The Learning Organization 15: 277-87. [CrossRef]

Mcardle, Kate, and Peter Reason. 2008. Action research and organization development. In Handbook of Organization Development. London: Sage, pp. 123-36.

Morse, Janice, Phyliis Stern, Juliet Corbin, Barbara Bowers, Kathy Charmaz, and Adele Clarke. 2009. Developing Grounded Theory—The Second Generation. Walnut Creek: Left Coast Press.

NDIS. 2018. National Disability Insurance Scheme Market Enablement Framework. Available online: https://www.ndis.gov.au/news / 996-new-framework-ensure-ndis-provider-markets-are-available-participants (accessed on 9 August 2021).

Norris-Tirrell, Dorothy, Jennifer Rinella, and Xuan Pham. 2018. Examining the career trajectories of nonprofit executive leaders. Nonprofit and Voluntary Sector Quarterly 47: 146-64. [CrossRef]

Osula, Bramwell, and Eddie Ng. 2014. Toward a collaborative, transformative model of non-profit leadership: Some conceptual building blocks. Administrative Sciences 4: 87-104. [CrossRef]

Palumbo, Rocco. 2016. Challenging servant leadership in the nonprofit sector: The side effects of servant leadership. The Journal of Nonprofit Education and Leadership 6: 81-98. [CrossRef]

Phipps, Kelly, and Mark Burbach. 2010. Strategic leadership in the nonprofit sector: Opportunities for research. Journal of Behavioral and Applied Management 11: 137.

Powell, Walter, and Pagtricia Bromley. 2020. The Nonprofit Sector: A Research Handbook. Palo Alto: Stanford University Press.

Reed, Debra. 2021. Exploration of Aspects of Strategic Leadership That Are Unique to Nonprofit Organizations. Doctoral dissertation, Concordia University Chicago, River Forest, IL, USA.

Roberts, Gary. 2020. Servant Leadership and Change: A Review of the Literature. In New Horizons in Positive Leadership and Change. Berlin: Springer, pp. 33-64.

Rosenbaum, David, Elizabeth More, and Peter Steane. 2016. Applying grounded theory to investigating change management in the nonprofit sector. SAGE Open 6: 2158244016679209. [CrossRef]

Rosenbaum, David, Elizabeth More, and Peter Steane. 2018. Planned organisational change management: Forward to the past? An exploratory literature review. Journal of Organizational Change Management 31: 286-303. [CrossRef]

Rosenbaum, David, and Elizabeth More. 2021. Towards a Strategic Change Management Framework for the Nonprofit Sector: The Roll-out of Australia's National Disability Insurance Scheme. In Effective Imnplementation of Transformation Strategies: How to Navigate the Strategy and Change Interface Successfully. Edited by Shelley Kirkpatrick, Danielle Tucker, Kate Hughes, Angelina Zubac and Ofer Zwikael. London: Palgrave Macmillan, under Publication.

Rowold, Jens, Lars Borgmann, and Kai Bormann. 2014. Which leadership constructs are important for predicting job satisfaction, affective commitment, and perceived job performance in profit versus nonprofit organizations? Nonprofit Management and Leadership 25: 147-64. [CrossRef]

Seyhan, Osman. 2014. A primer for transformational leadership in nonprofit sector. Yönetim Bilimleri Dergisi 11: 253-75.

Searing, Elizabeth. 2018. Determinants of the recovery of financially distressed nonprofits. Nonprofit Management and Leadership 28: 313-28. [CrossRef]

Shakely, Jack. 2004. Improving Leadership in Nonprofit Organizations. Hoboken: John Wiley \& Sons, vol. 208.

Sukoco, Badri, Yeti Lestari, Ely Susanto, Reza Nasution, and Indrianawati Usman. 2021. Middle manager capabilities and organisational performance: The mediating effect of organisational capacity for change. International Journal of Productivity and Performance Management. [CrossRef]

Sung, Wookjoon, and Changil Kim. 2021. A study on the effect of change management on organizational Innovation: Focusing on the mediating effect of members' innovative behavior. Sustainability 13: 2079. [CrossRef]

Taylor, Richard, Nuttaneeya Torugsa, and Anthony Arundel. 2020. Social innovation in disability nonprofits: An abductive study of capabilities for social change. Nonprofit and Voluntary Sector Quarterly 49: 399-423. [CrossRef]

Thach, Elizabeth, and Karen Thompson. 2007. Trading places: Examining leadership competencies between for-profit vs. public and non-profit leaders. Leadership \& Organization Development Journal 28: 356-75.

Van Dierendonck, Dirk. 2011. Servant leadership: A review and synthesis. Journal of Management 37: 1228-61. [CrossRef]

Weisbrod, Burton. 2000. To Profit or Not to Profit: The Commercial Transformation of the Nonprofit Sector. Cambridge: Cambridge University Press. 